\title{
The remuneration of the community pharmacist in the developing world: the case in Indonesia
}

\author{
Andi Hermansyah, Anila Impian Sukorini, Abdul Rahem \\ Faculty of Pharmacy Universitas Airlangga Surabaya Indonesia
}

\author{
Keywords \\ Community pharmacy \\ Pharmacist \\ Remuneration \\ Survey

\section{Correspondence} \\ Andi Hermansyah \\ Faculty of Pharmacy \\ Universitas Airlangga Indonesia \\ Nanizar Zaman Joenoes Building Level 4 \\ Campus C Universitas Airlangga \\ Jalan Mulyorejo \\ Surabaya \\ Indonesia \\ andi-h@ff.unair.ac.id
}

\begin{abstract}
Introduction: The remuneration of pharmacist is critical to ensure sustainability of pharmacist services. There has been limited study about pharmacist remuneration in Indonesia. Aim: This study aims to investigate pharmacist remuneration system in Indonesia. Methods: A nationwide community pharmacy survey was conducted involving 7,000 pharmacies. Questions around remuneration models and amounts, types of incentives and other financial benefits structured the questionnaire. Descriptive analysis was used to evaluate the findings. Results: Of 2,087 pharmacists participated in the survey, only 1,952 respondents were recorded. More than half of respondents did not receive any particular fees designated to compensate provision of cognitive services. Fixed monthly salary predominantly formed the structure of remuneration system with less than half of the respondents received additional incentives to top up this monthly salary. Conclusion: The current remuneration system which mainly relies on monthly salary basis may not be sustainable to support provision of pharmacist-led cognitive services.
\end{abstract}

\section{Introduction}

Community pharmacist has been known as an important element of the healthcare system that provides both pharmaceuticals and services to the communities (Moullin et al., 2013). Supporting health by enabling community pharmacists full potential in the delivery of cognitive services has become the main objective of pharmacy stakeholders in many Low and Middle-Income Countries (LMICs) (Miller \& Goodman, 2016). The provision of pharmacist-provided patient care services, however, is challenging in many of these countries, given the pertinent barriers revolve around pharmacy and health system infrastructure (Scahill, 2014; Hermansyah et al., 2016). One of the commonly perceived barriers is the lack of remuneration of the community pharmacist.

The remuneration of community pharmacists has been viewed as a facilitator for pharmacy practice change (Roberts et al., 2006). The expanding role of pharmacists, which marks more progressive interventions of pharmacists in the fields of medication management, health promotion and disease prevention, implies a specific remuneration structure. The contemporary remuneration structure of pharmacists in LMICs, which highly relies on dispensing and medicines markup, may not be sustainable to support the implementation of cognitive pharmacist services (Hashemi-Meshkini et al., 2013). This is also the case in Indonesia.

Multiple policy approaches have been established to change the practice of community pharmacy in Indonesia, including the provision of incentives in the form of minimum rates for pharmacist remuneration and payment for particular pharmacies working under the Universal Health Coverage programme (Hermansyah et al., 2018b). The incentivisation policy may highlight a novel approach for developing community pharmacy in the context of LMICs as these incentives were not influenced by the volume and/or profit margin from selling the pharmaceuticals. 
Nevertheless, the implementation has been far from satisfactory. The approach has been challenged by lack of coordination and lack of consensus leading to inconsistency and discrepancy of the actual payment for pharmacists. Apart from the troubled implementation, it is fair to say that the making of this policy did not take into account the characteristics and type of pharmacist remuneration in Indonesia (Hermansyah et al., 2018b).

There is evidence that the successful wide-scale implementation of cognitive services has been limited by the lack of remuneration for providing cognitive services (Bernsten et al., 2010; Houle et al., 2014). Unless this barrier is addressed, it is likely that any policies or approaches concerning practice change will fail. Therefore, this study aims to investigate the pharmacist remuneration model in Indonesia.

\section{Methods}

\section{Study design and settings}

A cross-sectional study was conducted in the form of a survey of community pharmacists across all 34 provinces in Indonesia. Only the pharmacist in charge represented each pharmacy. This study obtained ethics approval from the Research Ethics Committee of the Faculty of Public Health at the authors' institution.

\section{Study participants and recruitments}

There were 25,339 community pharmacies in Indonesia at the time of the study conducted. Using a margin of error of $1 \%$ and a confidence level of $95 \%$ resulted in 7,000 pharmacists as a minimum sample size. A registered community pharmacist in charge (or socalled first pharmacist) was recruited to participate in this study. At first, the researchers used a cluster sampling method based on province distribution with pharmacist identity for randomisation was obtained from the local pharmacist association. The sampling technique was then expanded using accidental sampling to obtain more responses.

\section{Study instruments}

This study utilised a questionnaire as an instrument, which asked about the type and amount of pharmacist remuneration, other financial benefits obtained by pharmacists and pharmacist preferences with respect to the remuneration model. The questionnaire was developed based on the references, discussion among the researchers as well as considered the phenomenon and facts related to pharmacist remuneration in Indonesia. The questionnaire was then tested for validity to a panel of experts (eight persons representing pharmacist practitioner, biostatistician, pharmacist organisation, academic, policymaker and administrator). This is to ensure the face and content validity of the questionnaire. The questionnaire was subsequently pilot-tested for both face validity and reliability to 20 pharmacists with some minor changes for the final version, mostly related to wording and numbering of the questionnaire form.

\section{Data collection}

This study used both online and printed survey forms. The printed questionnaire was sent to some local pharmacist associations for a limited number. The main means for data collection was an online survey distributed through a number of social media applications, i.e. WhatsApp, Line, Facebook, Twitter, Instagram and Telegram. Survey Monkey was used as the platform for the online survey. Data collection was conducted from September 2018 to March 2019. Participants who completed the survey received two credits for the licensure requirement and were assigned for a lucky draw to win five android tablets. Participants only had one chance to fill out the survey. In case there were multiple answers from a similar pharmacy, only the latest response was recorded. The pharmacist in charge could participate in the survey or pass the questionnaire to another pharmacist who was representing the pharmacy. In addition, reminder notification was made each month and distributed via the pharmacist association and its network. Participants were required to provide consent prior to fill out the questionnaire.

\section{Data analysis}

All response was recorded by the Survey Monkey system which then exported to SPSS Version 22 for further data analysis. Descriptive statistics of the frequency (\%) were used to describe the findings of the study.

\section{Results}

Of 2,087 pharmacists who participated in the study, only 1,952 pharmacists were deemed eligible. However, the number of complete responses in each question may vary. Table I summarises the characteristics of the respondents. The majority of respondents were female (78\%), aged $21-30$ years old $(48 \%)$, completed pharmacist programme, i.e. four years of Bachelor of Pharmacy and one-year prepharmacist programme (90\%), graduated after 2010 (62\%) and got monthly paid roughly IDR 2-5 million (67\%). 
Table I: Characteristics of respondents

\begin{tabular}{|c|c|}
\hline Characteristics & $\begin{array}{l}\text { Frequency } \\
\text { (\%) }\end{array}$ \\
\hline \multicolumn{2}{|l|}{ Gender $(n=1,767)$} \\
\hline - Male & $391(22 \%)$ \\
\hline - Female & $1,376(78 \%)$ \\
\hline \multicolumn{2}{|l|}{ Age in years $(n=1,211)$} \\
\hline - 21-30 & $586(48 \%)$ \\
\hline - $31-40$ & $457(38 \%)$ \\
\hline - 41-50 & $123(10 \%)$ \\
\hline - 51-60 & $31(3 \%)$ \\
\hline$\cdot>60$ & $14(1 \%)$ \\
\hline \multicolumn{2}{|l|}{ Latest educational level $(n=1,210)$} \\
\hline - Pharmacist & $1,097(91 \%)$ \\
\hline - Pharmacist and graduate programme & $113(9 \%)$ \\
\hline \multicolumn{2}{|l|}{ Year of graduation $(n=1,209)$} \\
\hline$\bullet<2000$ & $100(8 \%)$ \\
\hline - 2000-2010 & $390(32 \%)$ \\
\hline - $>2010$ & $719(62 \%)$ \\
\hline \multicolumn{2}{|l|}{$\begin{array}{l}\text { Take home pay received per month in IDR } \\
(n=1,200)\end{array}$} \\
\hline$\bullet<1,000,000$ & $14(1 \%)$ \\
\hline - $1,000,001-2,000,000$ & $161(13 \%)$ \\
\hline - $2,000,001-3,000,000$ & $379(32 \%)$ \\
\hline - $3,000,001-5,000,000$ & $414(35 \%)$ \\
\hline - $5,000,001-10,000,000$ & $156(13 \%)$ \\
\hline - $10,000,001-20,000,000$ & $50(4 \%)$ \\
\hline - $20,000,001-30,000,000$ & $16(1 \%)$ \\
\hline - $>30,000,000$ & $10(1 \%)$ \\
\hline
\end{tabular}

Table II shows the type of remuneration and/or benefits received by respondents. The respondents were commonly paid in the form of monthly salary (93\%). Only less than half of respondents received fees for professional services (44\%). In general, most of the respondents did not receive any other additional fees. However, they claimed that there is a remuneration increase periodically (62\%).

Table III identifies pharmacists' preferences regarding the ideal remuneration model. When asked about whether a pharmacist is entitled to receive a fee for practice, the majority of respondents agreed (82\%). Pharmacy owners, customers and the National health insurance agency (BPJS Health) are the top 3 payers preferred by the respondents to pay for pharmacist remuneration. With respect to the model of the remuneration, fee for service often sits in the most recommended model ( 5 out of 7 ) for paying pharmacists, followed by the capitation model ( 2 out of 7 ).
Table II: Type of remuneration of the respondent

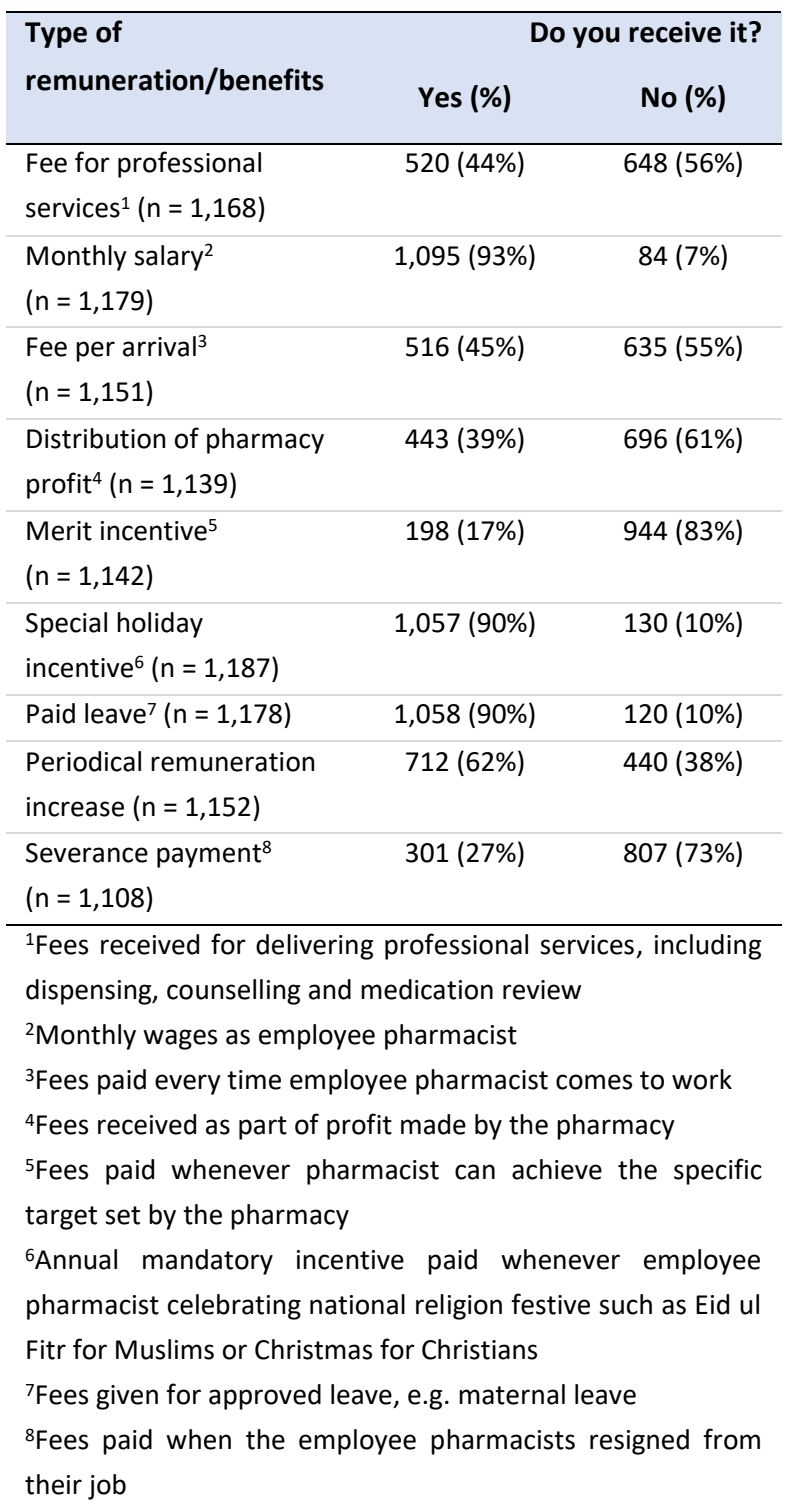

\section{Discussion}

There is an increasing need to deliver sustainable and high-quality health care to achieve the best possible outcomes in the most cost-effective fashion in Indonesia. This study argued that community pharmacy is in a unique position to offer the most cost-effective treatment to the general public. Not only cost-effective, but pharmacist also plays an important role to ensure that both pharmaceuticals and pharmacy services are delivered safely and effectively to the targeted population. However, results from this study show that despite the vital role of the pharmacist, compensation for their work has been minimal to support such a role. 
Table III: Respondent's preferences regarding payment model

\begin{tabular}{lcc}
\hline Question & Response & $\begin{array}{c}\text { Frequency } \\
\text { (\%) }\end{array}$ \\
\hline $\begin{array}{l}\text { Is a pharmacist entitled to } \\
\text { receive a fee for practice? }\end{array}$ & Yes & $625(82 \%)$ \\
$(n=762)$ & $137(18 \%)$ \\
\hline $\begin{array}{l}\text { Who should pay for pharmacist remuneration? } \\
\text { Central government }\end{array}$ & Yes \\
( $n=547)$ & No & $255(47 \%)$ \\
Local government & Yes & $236(53 \%)$ \\
( $n=519)$ & No & $283(54 \%)$ \\
National health insurance & Yes & $307(58 \%)$ \\
agency ( $n=533)$ & No & $226(42 \%)$ \\
Pharmacy association / & Yes & $149(31 \%)$ \\
the Guild ( $n=479)$ & No & $330(69 \%)$ \\
Customer / the patient & Yes & $395(67 \%)$ \\
( $n=586)$ & No & $191(33 \%)$ \\
Commercial insurance & Yes & $196(41 \%)$ \\
company ( $n=472)$ & No & $276(59 \%)$ \\
Pharmacy owner & Yes & $472(76 \%)$ \\
( $n=624)$ & No & $152(24 \%)$
\end{tabular}

What are the most suitable types of remuneration that should be paid by these parties?

Central government

Fee for service $\quad 58(18 \%)$

$(n=321)$

Capitation

$50(15 \%)$

Subsidy

$34(11 \%)$

Others

Local government

$(n=296)$

Capitation

$46(15 \%)$

Fee for service

$45(15 \%)$

Pay for

$33(11 \%)$

performance

Others

National health insurance company $(n=355)$

Capitation

$141(40 \%)$

Fee for service $55(16 \%)$

Pay for

$18(5 \%)$

performance

Others

32 (14\%)

the Guild $(n=232)$

Pay for

$27(12 \%)$

performance

Capitation

15 (6\%)

Others

Customer / the patient ( $n=414)$

Fee for service

145 (35\%)

User charge $129(31 \%)$

Pay for

$29(7 \%)$

performance

Others

$\begin{array}{lll}\text { Commercial insurance } & \text { Fee for service } & 49(18 \%) \\ \text { company }(n=268) & \text { Capitation } & 43(12 \%) \\ & \text { Pay for } & 22(8 \%) \\ & \text { performance } & \\ & \text { Others } & \\ \text { Pharmacy owner }(n=457) & \text { Fee for service } & 124(27 \%) \\ & \text { Pay for } & 88(19 \%) \\ & \text { performance } & \\ & \text { User charge } & 37(8 \%)\end{array}$

Most pharmacists in this study only received a monthly salary and another minimum additional fee resulting in the range of IDR 2-5 million (USD 150-350) as the income that they bring home every month. Given their roles and responsibilities as mandated in the Presidential Decree 73 of 2016 (Hermansyah et al., 2020), this seems inadequate to pay for pharmacist practice. Fairly speaking, such amount is equivalent to the minimum payment set by the government for the blue-collar worker, which absolutely highlights a contrasting spectrum of responsibilities with professionals such as pharmacists (Siregar, 2020). As the workload of pharmacists is increasing, particularly after the introduction of Universal Health Coverage which may imply an increased risk of their job, such amount of remuneration may not necessarily portray a proper compensation for the frontline healthcare workers like pharmacists.

The underlying objective of remuneration to pharmacists is to support them to deliver cognitive services. A practising community pharmacist is believed to have invaluable skills acquired from university-based training and experiential learning. Such predicate suggests that they deserve to be fairly compensated according to the standard of professional healthcare providers. This is why most respondents in this study believed that they should be paid for their professional contributions.

Pharmacists are also aware that they cannot rely on the government to pay for their work. Interestingly, pharmacy owners were commonly selected as the most recommended payer for pharmacy practice. This is perhaps related to the fact that the majority of pharmacists in Indonesia work as employee pharmacists (Hermansyah et al., 2018a). Despite the policy that community pharmacy only operates under the full authority of pharmacists, ownership of pharmacy in Indonesia is not restricted to pharmacists only. Any individuals or companies can own a pharmacy leading to most pharmacies owned by non-pharmacist. Arguably, ownership may determine the vision and mission of a pharmacy in delivering pharmaceutical care, and to some extent, it may influence pharmacist remuneration structure (Athiyah et al., 2019). With most pharmacists working as an employee, it might be challenging to negotiate remuneration, for instance, professional fee, unless the owners are aware the significance of delivering professional pharmacy services. This can be an insight for the existing employee pharmacists to convey a message that pharmacy services should be properly remunerated.

It is also not surprising that the customer sits in second place for the most recommended payer. In the short run, charging customers directly for service can be an 
effective - and the easiest - alternative to collect remuneration for pharmacists. The pharmacy can determine the rate and the customer, or the patient is at the position of "less of freedom" given that they will require the services or the pharmaceuticals. However, pharmacies often offer services at a low charge or even most of the time, free of charge (Anderson \& Thornley, 2014). This will be problematic for most pharmacies to initiate such payment. In the long run, charging customers can be feasible if the customers or patients recognise and experience the positive outcomes of the services. It may not be difficult to charge customers. What makes it difficult is to show the value and benefits behind the payment. Accordingly, fee for service is the perfect remuneration model for such case, which is also illustrated as the most selected remuneration model for community pharmacists in Indonesia.

Fee for service model is not new to community pharmacists in Indonesia. Prior to the implementation of Universal Health Coverage in 2014, the former insurance model in Indonesia used fees for services to pay pharmacy practice (Agustina et al., 2019). This model took place between 1992 and 2013 in particular pharmacies affiliated with the national health insurance agency. Fee for service is the traditional payment model in many countries to remunerate pharmacists. The benefits are twofold; pharmacists can tailor particular services suit to patient's needs, and patients can opt for services and be flexible with the services provided by the pharmacists. However, the fee for service also exerts some disadvantages; particularly, it lacks accountability as there is uncertainty about the necessary service that should be provided to the customers and how it will cost the customers. There is no denying that fee for service is financially beneficial for providers, but in the long term, it is an unsustainable system that may lead to a lot of waste, unnecessary and perhaps inaccurate services.

The implementation of a national remuneration system is quite challenging in the context of Indonesia. The findings of this study showed that the level and type of remuneration varied among pharmacists. Implementing remuneration standards to community pharmacists is a multistage, collaborative process with a significant and complex interplay of stakeholders' interests. A pilot study focusing on learning the effective development and implementation of such standards might be required. The results from the pilot study can be an initial assessment to understand pharmacy service utilization, pharmacist acceptance and community pharmacy viability. In this process, remuneration planning and design are critical as it should encompass regulatory requirements, government responsibilities and pharmacy characteristics as most pharmacies in Indonesia are operated independently and owned by nonpharmacist. At the end of the day, the quality and competence of the pharmacist will determine the remuneration. An innovative pharmacist may have the potentials to gain more payment. However, it is not only about the payment; the positive outcome of the care is also substantial to help facilitating the ideal remuneration system for Indonesian pharmacists.

This study does have limitations that should be considered. First, this study used accidental sampling to recruit participants, which may not be accurate to portray the overall picture of the Indonesian community pharmacist. Second, the questionnaire was self-administered, highlighting that there is always a potential for recall and response biases from the respondents when answering the questions. Third and finally, it is also important to note that there is a variation of response between questions which may illustrate a lack of uniformity in drawing a conclusion for this study. Therefore, it is advised to interpret the findings of this study cautiously. Nevertheless, to the best of the authors' knowledge, this is the first nationwide survey collecting data about community pharmacist remuneration in Indonesia. This can be an important piece of information to support the existing incentivisation policy and to provide an overview of the remuneration model for community pharmacies in Indonesia. Further research is warranted to seek an effective model of remuneration in association with the outcome of the services.

\section{Conclusion}

Community pharmacists in Indonesia were commonly paid on the basis of monthly salary with a minimum additional fee provided to pay for the services. Such a remuneration model is indeed inadequate and not supportive to trigger professional and cognitive services in the community pharmacy. As pharmacists are uniquely positioned in the frontline of care, there is an imperative to properly compensate pharmacists considering their responsibilities, risks and qualifications.

\section{References}

Agustina, R., Dartanto, T., Sitompul, R., Susiloretni, K. A., Achadi, E. L., Taher, A., Wirawan, F., Sungkar, S., Sudarmono, P., \& Shankar, A. H. (2019). Universal health coverage in Indonesia: concept, progress, and challenges. The Lancet, 393(10166), 75-102. https://doi.org/10.1016/S01406736(18)31647-7

Anderson, C., \& Thornley, T. (2014). "It's easier in pharmacy": why some patients prefer to pay for flu jabs rather than use 
the National Health Service. BMC Health Services Research, 14(1), 35. https://doi.org/10.1186/1472-6963-14-35

Athiyah, U., Setiawan, C. D., Nugraheni, G., Zairina, E., Utami, W., \& Hermansyah, A. (2019). Assessment of pharmacists' knowledge, attitude and practice in chain community pharmacies towards their current function and performance in Indonesia. Pharmacy practice, 17(3), 1518-1518. https://dx.doi.org/10.18549\%2FPharmPract.2019.3.1518

Bernsten, C., Andersson, K., Gariepy, Y., \& Simoens, S. (2010). A comparative analysis of remuneration models for pharmaceutical professional services. Health Policy, 95(1), 19. https://doi.org/10.1016/j.healthpol.2009.11.008

Hashemi-Meshkini, A., Keshavarz, K., Nikfar, S., Vazirian, I., \& Kebriaeezadeh, A. (2013). Pharmacists remuneration models in Iran and selected countries: a comparative study. Iranian Journal of Pharmaceutical Research: IJPR, 12(4), 995

Hermansyah, A., Sainsbury, E., \& Krass, I. (2016). Community pharmacy and emerging public health initiatives in developing Southeast Asian countries: a systematic review. Health \& Social Care in the Community, 24(5), e11-e22. https://doi.org/10.1111/hsc.12289

Hermansyah, A., Sainsbury, E., \& Krass, I. (2018a). Investigating the impact of the universal healthcare coverage programme on community pharmacy practice. Health \& Social Care in the Community, 26(2), e249-e260. https://doi.org/10.1111/hsc.12506

Hermansyah, A., Sainsbury, E., \& Krass, I. (2018b). Multiple policy approaches in improving community pharmacy practice: the case in Indonesia. BMC Health Services Research, 18(1), 449. https://doi.org/10.1186/s12913-018-3258-8

Hermansyah, A., Wulandari, L., Kristina, S.A., \& Meilianti, S. (2020). Primary health care policy and vision for community pharmacy and pharmacists in Indonesia. Pharmacy Practice (Granada), 18(3). https://doi.org/10.18549\%2FPharmPract.2020.3.2085

Houle, S.K., Grindrod, K.A., Chatterley, T., \& Tsuyuki, R.T. (2014). Paying pharmacists for patient care: a systematic review of remunerated pharmacy clinical care services. Canadian Pharmacists Journal/Revue des Pharmaciens du Canada, 147(4), 209-232. https://doi.org/10.1177\%2F1715163514536678

Miller, R., \& Goodman, C. (2016). Performance of retail pharmacies in low-and middle-income Asian settings: a systematic review. Health policy and planning, 31(7), 940953. https://doi.org/10.1093/heapol/czw007

Moullin, J.C., Sabater-Hernández, D., Fernandez-Llimos, F., \& Benrimoj, S.I. (2013). Defining professional pharmacy services in community pharmacy. Research in Social and $\begin{array}{lll}\text { Administrative Pharmacy, 9(6), 989-995. } & \text { 9 }\end{array}$ https://doi.org/10.1016/j.sapharm.2013.02.005

Roberts, A.S., Benrimoj, S.I., Chen, T.F., Williams, K.A., \& Aslani, P. (2006). Implementing cognitive services in community pharmacy: a review of facilitators used in practice change. International Journal of Pharmacy Practice, 14(3), 163-170. https://doi.org/10.1211/ijpp.14.3.0002

Scahill, S. (2014). Barriers to effective pharmacy practice in lowand middle-income countries. Integrated Pharmacy Research and Practice, 3, 25. https://doi.org/10.2147/IPRP.S35379
Siregar, T.H. (2020). Impacts of minimum wages on employment and unemployment in Indonesia. Journal of the Asia Pacific Economy, 25(1), 62-78. https://doi.org/10.1080/13547860.2019.1625585 